\title{
Potential of Bacillus cereus (Accession number KY7506901) on Di (2-Ethylhexyl) Phthalate Degradation and its Characterization by LCMS
}

\author{
Madhavi Rashmi ${ }^{1}$, Sonal Suman ${ }^{2}$ and Tanuja Singh ${ }^{1 *}$ \\ 'Department of Botany and Biotechnology, T.P.S. College, Patliputra University, Patna - 800020, Bihar, India; \\ tanujapatnabotany@gmail.com \\ ${ }^{2}$ Department of Botany and Biotechnology, T.P.S. College, Patliputra University, Patna - 800020, Bihar, India
}

\begin{abstract}
The present work has been undertaken for remediating phthalate exposure in the environment. The microbial strain was isolated by enrichment culture technique from the rubbish dump space close to Patna that was contaminated with phthalates for higher degradation ability. The isolated microbial strain T7 was designated as Bacillus cereus after Gram-staining, biochemical characterization, 16S-rRNA sequence and phylogenetic studies. The isolate had the power to utilize $250 \mu \mathrm{g} / \mathrm{ml}$ Di (2-ethyl Hexyl Phthalate) (DEHP) dose taken from $10 \mathrm{mg} / \mathrm{ml}$ (DEHP) stock solution within the growth medium. The optimum $\mathrm{pH}$ and temperature for DEHP degradation were 8.5 at $37^{\circ} \mathrm{C}$. The isolated bacterial strain T7 may allow up to $10 \% \mathrm{NaCl}$ in minimal salt medium that was enrich with DEHP. The metabolic end product obtained after LCMS was bis [3-(oxolan-2-yl) propyl] nonanedioate having chemical formula $\mathrm{C}_{23} \mathrm{H}_{40} \mathrm{O}_{6}$. This work provides some new proof for soil rectification by Bacillus species.
\end{abstract}

Keywords: Biochemical characterization, Biodegradation, DEHP, 16sr-RNA, LC-MS

\section{Introduction}

Phthalates are a class of compounds which is made up of esters of phthalic anhydride, used as plasticizers. DEHP is amongst the most commonly used plasticizers which are used in many fields such as in industrial, medical and domestic applications. The hydrocarbon chain of PAEs remains long hence it has been considered most resistant ${ }^{1}$. Polyvinyl Chloride (PVC) contains DEHP and when it is disposed of in large excess then its leaching in the environment occurs ${ }^{2}$. DEHP affects humans by the aid of damage of liver, developmental and reproductive effects ${ }^{3-6}$. They have become omnipresent and may be found in the atmosphere, activated sludge, soil, solid waste compost and river, marine and in drinking water ${ }^{7}$. Phthalates have been present in humans such as in blood stream, fluid of amniotic sac, salivary gland secretions and mammary gland secretions and excreted through the excretion process $^{8}$. Biological or physicochemical degradation is a way to degrade DEHP from the contaminated environment ${ }^{9}$. Microorganisms could degrade DEHP solely which is a derivative of carbon and energy $y^{10-12}$.

In the present study, the focus was isolation, identification and characterization of potent DEHP-degrading microbial strain from garbage dump soil and to know its degradation potential towards the degradation of DEHP. To optimize the conditions for higher degradation ability, effect of temperature, $\mathrm{pH}$ and salinity have also been investigated.

\section{Materials and Methods}

\subsection{Chemicals}

The higher grades of pure reagents were used and distilled water was used throughout the experiments. DEHP was used solely as a derivative of carbon. It was acquired from Accu Standard, Inc. As a medium for DEHP, corn oil was used. It was obtained from Nieshiel Pvt. Ltd. Duplicate experiments were performed.

\subsection{Collection of the Sample}

Soil sample was collected from $10 \mathrm{~cm}$ depth in $1 \mathrm{~m}^{2}$ chosen area which was heavily contaminated with plastics. The sample was collected aseptically with the aid of a sterile spatula, scalpels, gloves and plastic bottles and was fully labelled with description and date. The sample was collected from a rubbish dump space near Primary Health centre, Sampatchak, Patna.

${ }^{*}$ Author for correspondence 


\subsection{Isolation of Plasticizer Degrading Strain and Cultivation Medium}

For enrichment culture, the inoculum was started by inoculating $300 \mathrm{ml}$ of Minimal Supplement Media (MSM) with $1 \mu \mathrm{g}$ soil sample along with phthalate. The MSM consisted of the chemicals $(\mathrm{mg} / \mathrm{l}):\left(\mathrm{NH}_{4}\right)_{2} \mathrm{SO}_{4}, 1,000 ; \mathrm{KH}_{2} \mathrm{PO}_{4}, 800 ; \mathrm{K}_{2} \mathrm{HPO}_{4}$, 200; $\mathrm{MgSO}_{4} \cdot 7 \mathrm{H}_{2} \mathrm{O}, 500 ; \mathrm{FeSO}_{4}, 10 ; \mathrm{CaCl}_{2}, 50$ and the $\mathrm{pH}$ was maintained $7.0 \pm 0.1^{8}$. The DEHP-degrading cultures were obtained by transfer of enrichments at approximately 7 days intervals on the basis of consumption of DEHP, by inoculating 1.0 $\mathrm{ml}$ of the culture to a new test tube containing $100 \mathrm{ml}$ of freshly made MSM with gradually increasing concentrations of DEHP $(1 \text { to } 10 \mathrm{mg} / \mathrm{l})^{13}$. Bacteria in enrichment cultures displaying the ability to utilize DEHP solely as a derivative of carbon source were diluted in MSM and plated on nutrient agar. Some wellseparated colonies of different morphologies were formed after the incubation of $48 \mathrm{~h}$ at $37^{\circ} \mathrm{C}$, these were again streaked onto fresh nutrient agar plates to further purify these strains.

\subsection{Screening of the Potential Plasticizer Degrading Strain from the Isolates}

The bacterial strains isolated were grown on nutrient agar with different concentrations of DEHP to know the survival capacity of strains at relatively different higher concentrations of DEHP. An increase in Optical Density (OD) at $600 \mathrm{~nm}$ was measured in MSM broth and bacterial colonies were observed on NA plates ${ }^{14}$. Healthy and proliferating phthalate metabolizing strains were obtained at different concentrations of DEHP which were selected for further studies.

\subsection{Characterization and identification of Plasticizer Degrading Strain}

Colony morphology was observed by cultivating the selected bacterial isolates on nutrient agar plates. Morphological characters were determined by visual observation as well as by using trans illuminator and light microscopy. The gram staining technique was employed for the differentiation between grampositive and gram-negative bacteria ${ }^{13}$.

\subsection{Degradation on the basis of Different Physiological Conditions}

\subsubsection{Effect of Temperature}

The potential of phthalate degrading bacterial strain was studied at different temperatures 24,37 and $50^{\circ} \mathrm{C}$. The study was performed in triplicate for each temperature. The growth was evaluated by taking optical density at $600 \mathrm{~nm}$ after 48 hrs by UV-visible spectrophotometer (Labtronics model no: LT 2900).

\subsubsection{Effect of $p H$}

$300 \mathrm{ml}$ MSM media at different $\mathrm{pH}(5.5,7.0,8.5,10.5)$ was prepared and maintained at $37 \mathrm{C}$ in an incubator. The bacterial growth was measured at $600 \mathrm{~nm}$ after $48 \mathrm{~h}$ of incubation by using UV-visible spectrophotometer.

\subsubsection{Effect of salt}

The bacterial suspension was inoculated in each salt concentration of $(5 \%, 10 \%$ and $15 \% \mathrm{NaCl})$ containing $300 \mathrm{ml}$ MSM media and transferred to the incubator at $37^{\circ} \mathrm{C}$ for 48 $\mathrm{h}$; bacterial growth was measured at $600 \mathrm{~nm}$ by taking optical density of the culture.

\subsection{Molecular Characterization}

\subsubsection{S Ribosomal RNA Method}

\subsubsection{Genomic DNA Extraction}

DNA was extracted from $48 \mathrm{~h}$ old culture broth using DNA isolation kit according to the manufacture instructions and its quality was evaluated on $0.8 \%(\mathrm{w} / \mathrm{v})$ Agarose gel (Hi media) in on electrophoresis apparatus (Bio-rad).

\subsubsection{Polymerase Chain Reaction Amplification}

Fragment of $16 \mathrm{~s} r$ RNA gene was amplified by PCR program with universal primer $8 \mathrm{~F}$ (5'AGAGTTTGATCCTGGCTCAG3') and 1541R (5’AAGGAGGTGATCCAGCC CA3).

\subsubsection{Sequencing of the PCR}

16s rRNA analysis was performed by Yaazh Xenomics, Coimbatore, India. The product was compared to sequences within the NCBI gene bank database with the BLAST (Basic Alignment Gene Bank Tool). The blast results having closely related sequences was performed with the query sequence of phylogeny analysis followed by multiple sequence alignment. The program MUSCLE 3.7 was used for multiple alignments of sequences ${ }^{14}$. The program $\mathrm{G}$ blocks $0.91 \mathrm{~b}$ cured the resulting aligned sequences. This $\mathrm{G}$ blocks eliminates poorly aligned positions and divergent regions $s^{15}$. The program Tree Dyn 198.3 was used for the rendering of tree ${ }^{16}$.

\subsubsection{Analytical Method}

The intermediate metabolites were analyzed by Liquid Chromatography-Mass Spectrometry (LC-MS) (Jamia Hamdard, New Delhi.). The Electrospray Ionization (ESI) was used as a source, employing a full scan for the mass range of 50e400. ESI mass spectral data were obtained in positive scan mode and temperature of the probe was $300^{\circ} \mathrm{C}$. 


\section{Results}

\subsection{Identification of DEHP Degrading Strain}

Microscopic observation after gram staining revealed that the isolated bacterial strain named T7 was a Gram-negative, motile and rod shaped. The colony produced on a culture medium plate was a light colony with oval and irregular in shape and the margin was smooth and elevated ${ }^{15}$. The 16 s ribosomal RNA method from isolated strain T7 revealed that it had been B. cereus Gen Bank accession no. (KY750689) with maximum identity (96\%) in step with the NCBI database as depicted in (Figure 1). The expansion of B. cereus with DEHP is because of the derivative of carbon and energy source. Bacterial biomass increased over the whole period of incubation as DEHP was depleted. Bacillus species are outspread in nature and have been reported to metabolize DEHP ${ }^{16}$.

\section{Phylogenetic Tree}

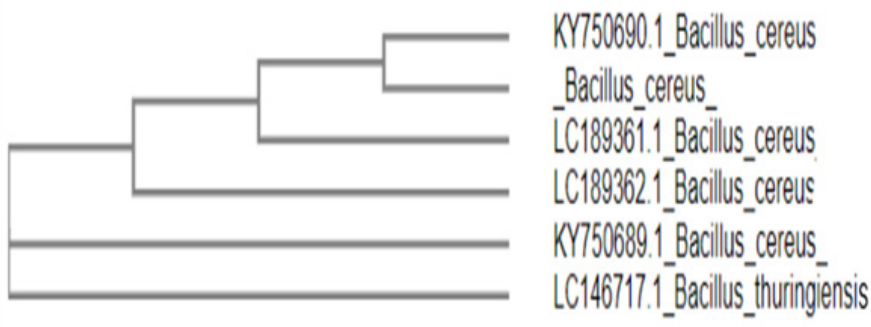

Figure 1. Phylogenetic tree of Bacillus_cereus. The sequence bar equals 0.02 changes per nucleotide position.

\subsection{Effect of Different Environmental Parameters on DEHP Degradation}

\subsubsection{Degradation at a various $p H$}

Maximum activity was shown at $\mathrm{pH} 8.5$ on $10^{\text {th }}$ day of incubation as illustrated in (Figure 2).

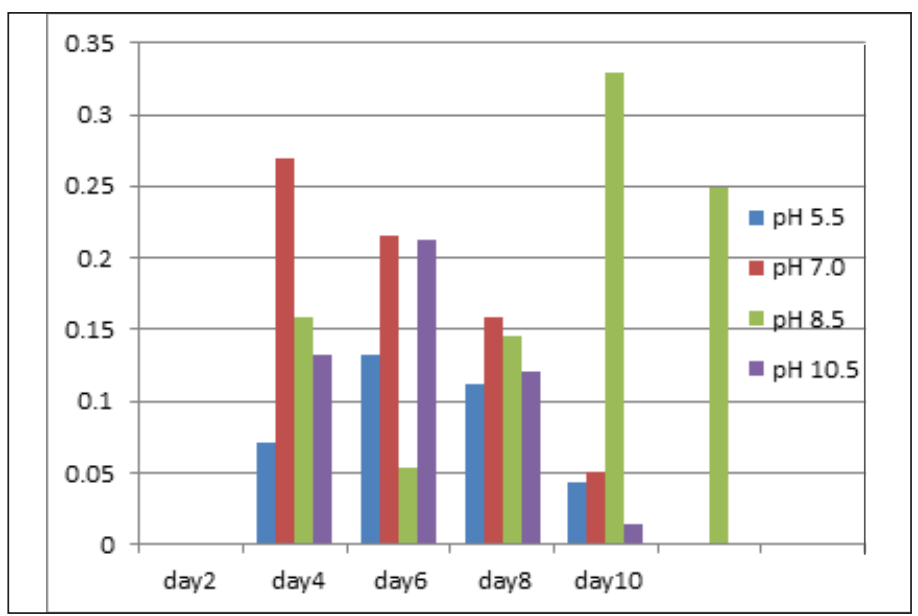

Figure 2. Showing effect of $\mathrm{pH}$ on degradation.
X-axis showing duration of days of an incubation while Y-axis showing optical density.

\subsubsection{Degradation at a Various Temperature}

As the temperatures rises the degradation rate becomes slower. The temperature for degradation of isolated strain B. cereus which was optimum, evaluated at $37^{\circ} \mathrm{C}$. On $2^{\text {nd }}$ day of incubation as shown in (Figure 3).

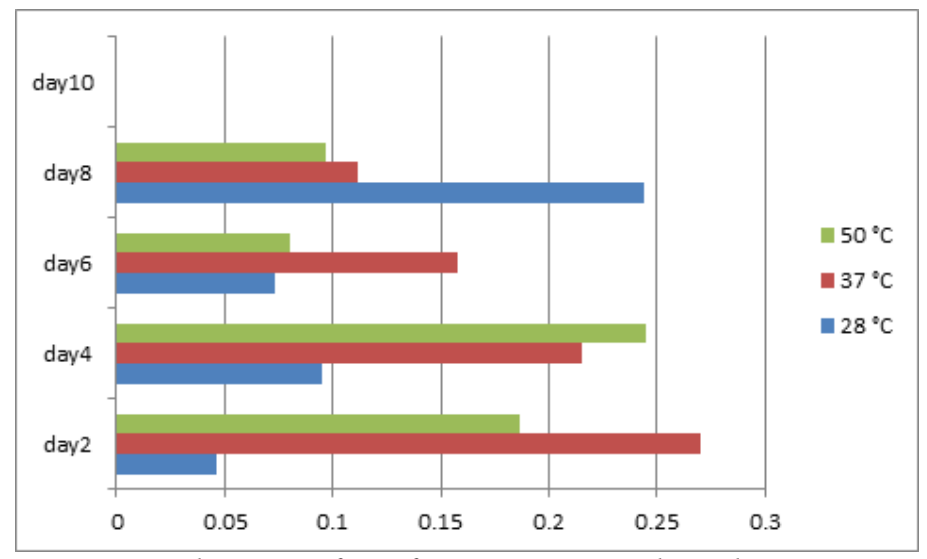

Figure 3. Showing effect of temperature on degradation.

\subsubsection{Degradation at a Various Salt Concentrations}

Salinity is one of the important factors that affect microbial growth degradation. The degradation was higher at $10 \% \mathrm{NaCl}$ concentration on $2^{\text {nd }}$ day of $\mathrm{OD}$ in the present investigation as in (Figure 4).

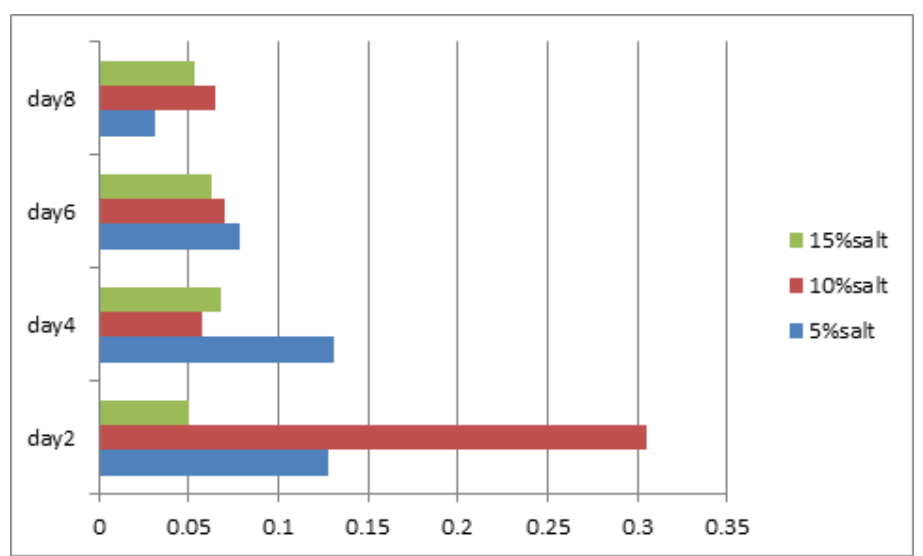

Figure 4. Showing effect of salinity on rate of degradation.

\subsection{Biochemical Characterization}

Biochemical tests were performed using Bergey's Manual of Systemic Bacteriology for biochemical characterization. 
Table 1. Biochemical test result

\begin{tabular}{|l|l|c|}
\hline & Biochemical tests & Bacterial strain \\
\hline & & T7 \\
\hline 1 & Amylase & + \\
\hline 2 & Casein Hydrolysis & + \\
\hline 4 & Catalase & + \\
\hline 5 & Gelatin Hydrolysis & - \\
\hline 6 & Nitrate Reduction & + \\
\hline 7 & Citrate Utilization & + \\
\hline 8 & Methyl Red & + \\
\hline 9 & Voges Proskuer & - \\
\hline 10 & Lactose & + \\
\hline 11 & Dextrose & + \\
\hline 12 & Sucrose & + \\
\hline 13 & HzS production & - \\
\hline 14 & Citrate utilization & - \\
\hline
\end{tabular}

\subsection{Identification of Metabolites by LC-MS/MS}

The metabolites of DEHP degradation by $B$. cereus were extracted at different time intervals and identified by LC-MS (Liquid Chromatography-Mass Spectrometry) method. The metabolites were identified by comparing the mass spectrum (RT) with published mass spectra from the database at a particular retention time. The molecular mass of the degraded compound obtained was 413.29 at retention time $10.13 \mathrm{~min}$. as depicted in (Figure 3). And the metabolic end product obtained was bis [3-(oxolan-2-yl) propyl] nonanedioate. Chemical Formula: $\mathrm{C}_{23} \mathrm{H}_{40} \mathrm{O}_{6}$

The mass spectral analysis of compound showed the parent ion peak at m/z 321.25 as shown in (Figure 6). The fragment peaks patterns showed at $\mathrm{m} / \mathrm{z}$ ion peaks at $\mathrm{m} / \mathrm{z} 301.15$ base peak (Figure 6) presents the metabolic intermediates identified in DEHP degradation by $B$. cereus but their characterization was not possible because they could not be isolated.

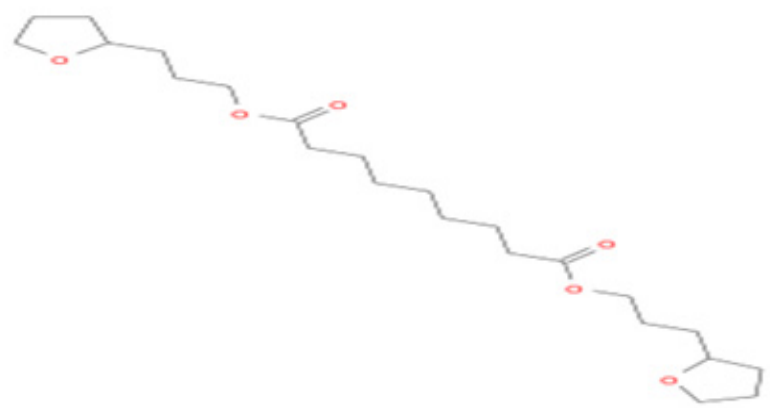

DTXCIDOOZ75998

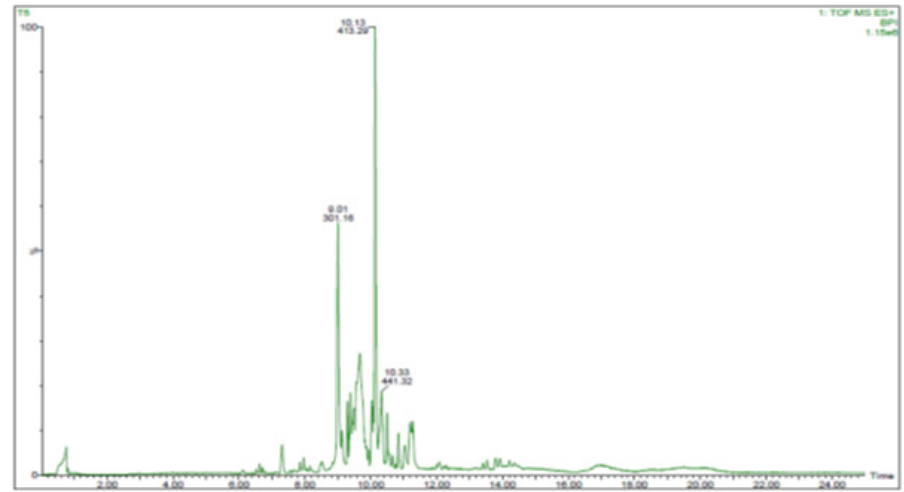

Figure 5. DEHP degradation metabolic intermediates identified by LC-MS.

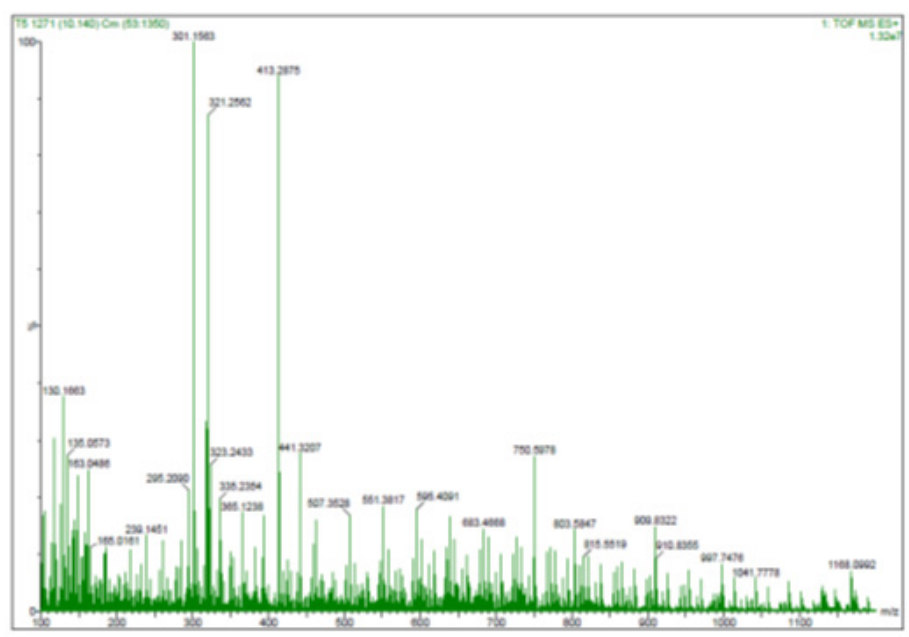

Figure 6. The mass spectrum of DEHP degraded intermediate compounds, $\mathrm{X}$-axis contains mass in relative to charge ratio $(\mathrm{m} / \mathrm{z})$ while $y$-axis contains a relative abundance

\section{Discussion}

Environmental pollution is a major global problem. Bioremediation is one of the ways to reduce the environmental pollution. In the present research work, a microbial strain T7 was efficient to consume DEHP solely as a derivative of carbon and energy was isolated from soil sample which was taken from the rubbish dump space and then was identified as $B$. cereus based on its morphology, gram staining method, different biochemical estimations, and 16S rRNA sequence analysis. 16S rRNA gene sequence analysis of strain T7 showed homology (96\%) with that of B. cereus. This indicates that strain T7 is possibly a new species of the genus Bacillus. There is scanty of reports on DEHP degradation by Bacillus cereus strain from rubbish dump soil as in our knowledge. The colonies of the isolated strain cultured in 18-24 hr showed ivory, opaque and round morphology ${ }^{17}$. The optimum $\mathrm{pH}$ and temperature for DEHP degradation by strain T7 are quite 
similar to many reported strains. Previous studies have shown that the degradation of DEHP is particularly sensitive to low $\mathrm{pH}$ values. The $\left[\mathrm{H}^{+}\right]$in the culture medium highly affects the growth of bacteria since $\mathrm{pH}$ value limits the enzymes activity hence degradation of DEHP was particularly sensitive to low $\mathrm{pH}$. The degradation rate and the OD at $600 \mathrm{~nm}$ of degrading strain increased speedily when the $\mathrm{pH}$ of the culture was apparently increased ${ }^{18}$. The highest biodegradation rate of DEHP was achieved at the ranges from 7.0 to 8.5 at $37^{\circ} \mathrm{C}$ in the present study. Recently, several microbial strains have been isolated from numerous environments, however only a few researches have centered on DEHP degradation within the presence of salt. Cortés-Lorenzo et al., 2014 have been reported that the diffusion potential of strains with superior salinity tolerance increases that have an effect on their metabolic activities. Though strain T7 exhibited a same trend in this higher salinity levels reduced the bacterial growth rates leading to longer degradation times, it may tolerate up to $10 \%$ of $\mathrm{NaCl}$ concentration. There is no any reported evidence regarding characterization of metabolic end product of DEHP by LC-MS analysis. This characteristic suggests that strain T7 would be a promising candidate for the bioremediation of DEHP-contaminated soil.

\section{Conclusion}

This study showed the results obtained that DEHP could be rapidly degraded by $B$. cereus isolated from soil contaminated with plastic wastes. The results suggest that DEHP can be degraded by natural bacteria. Numerous researches have been published on degradation of phthalate however these studies inefficient in some views such as efficient DEHP degradation at higher concentrations, elucidation of DEHP degradation pathway, the kinetics of DEHP degradation and identification of genes responsible for phthalate degradation by 16s rRNA and identification of its metabolite by LC-MS. Extensive research in the above aspects is required to remediate these pollutants from the environment.

\section{Acknowledgments}

The authors acknowledge Principal, T.P.S. College, Patliputra University, Patna, Bihar, for providing lab facilities for the presented research work. This research work did not receive any funding from any funding agencies.

\section{References}

1. Chang BV, Yang CM, Cheng CH, Yuan SY. Biodegradation of phthalate esters by two bacteria strains. Chemosph.
2004; 55:533-8. PMid: 15006506. https://doi.org/10.1016/j. chemosphere.2003.11.057

2. Latorre I, Hwang S, Sevillano, M, Montalvo-Rodriguez R. PVC biodeterioration and DEHP leaching by DEHP-degrading bacteria. Int Biodeterior Biodegr. 2012b; 69:73-81. PMid: 22736894 PMCid: PMC3377483. https://doi.org/10.1016/j. ibiod.2011.12.011

3. Lomenick JP, Calafat AM, Castro MSM, Mier R, Stenger P, Foster MB, et. al. Phthalate exposure and precocious puberty in females. J Pediatr. 2010; 156:221-5. PMid: 19892364. https://doi.org/10.1016/j.jpeds.2009.09.047

4. Lo D, Wang YT, Wu MC. Hepatoprotective effect of silymarin on Di (2-ethylhexyl) Phthalate (DEHP) induced injury in liver FL83B cells. Environ Toxicol Pharmacol. 2014; 38:112-8. PMid: 24934613. https://doi.org/10.1016/j.etap.2014.05.005

5. 5. Zong T, Lai L, Hu J, Guo M, Li M, Zhang L, et al. Maternal exposure to Di-(2-ethylhexyl) Phthalate disrupts placental growth and development in pregnant mice. J Hazard Mater. 2015; 297:25-33. PMid: 25935407. https://doi.org/10.1016/j. jhazmat.2015.04.065

6. Chen H, Zhang W, Rui BB, Yang SM, Xu WP. Di (2-ethylhexyl) Phthalate exacerbates non-alcoholic fatty liver in rats and its potential mechanisms. Environ Toxicol Pharmacol. 2016; 42:3844. PMid: 26773359. https://doi.org/10.1016/j.etap.2015.12.016

7. Net S, Delmont A, Sempere R, Paluselli A, Ouddane B. Reliable quantification of phthalates in environmental matrices (air, water, sludge, sediment and soil): A review. Science of the Total Environment, 2015; 515-516:162-80. PMid: 25723871. https:// doi.org/10.1016/j.scitotenv.2015.02.013

8. Mankidy R, Wiseman S, Ma Hong, Giesy JP. Biological impact of phthalates. Toxicol Letters. 2013; 2171:5-58. PMid: 23220035. https://doi.org/10.1016/j.toxlet.2012.11.025

9. 9. Magdouli S, Daghrir R, Brar SK, Drogui P, Tyagi RD. Di 2-ethylhexyl Phthalate in the aquatic and terrestrial environment: a critical reWview J Environ Manage. 2013; 127:36-49. PMid: 23681404. https://doi.org/10.1016/j.jenvman.2013.04.013

10. Baek JH, Gu MB, Sang BI, Kwack SJ, Kim KB, Lee BM. Risk reduction of adverse effects due to Di-(2-ethylhexyl) Phthalate (DEHP) by utilizing microbial degradation. J Toxicol Environ Health, Part A. 2009; 72:138-94. PMid: 20077210. https://doi. org/10.1080/15287390903212733

11. Meng X, Niu G, Yang W, Cao X. Di (2-ethylhexyl) Phthalate biodegradation and denitrification by a Pseudoxanthomonas sp. strain. Bioresour Technol. 2015; 180:356-9. PMid: 25596917. https://doi.org/10.1016/j.biortech.2014.12.071

12. Pradeep S, Josh MS, Binod P, Devi RS, Balachandran S, Anderson RC, et al. Achromobacter denitrificans strain SP1 efficiently remediates Di (2-ethylhexyl) Phthalate. Ecotoxicol Environ Saf. 2015a; 112:114-21. PMid: 25463861. https://doi.org/10.1016/j. ecoenv.2014.10.035

13. Aneja KR. Experiments in Microbiology plant pathology and Biotechnology Fourth ed. New Delhi: New Age International (P) Ltd, Publishers; 2007; 157:245-75. 
14. Edgar RC. MUSCLE multiple sequence alignment with high accuracy and high throughput. Nucleic Acids Res. 2004; 32:1792-7. PMid: 15034147 PMCid: PMC390337. https://doi. org/10.1093/nar/gkh340

15. Talavera G, Castresana J. Improvement of phylogenies after removing divergent and ambiguously aligned blocks from protein sequence alignments. Systematic Bio. 2007; 56:564-77. PMid: 17654362. https://doi.org/10.1080/10635150701472164

16. Dereeper A, Guignon V, Blanc G, Audic S, Buffet S, Chevenet F, Dufayard JF, Guindon S, Lefort V, Lescot M, Claverie JM,
Gascuel O. Phylogeny for robust phylogenetic analysis for the non-specialist. Nucleic Acids Res. 2008; 36(S2):W465-9. PMid: 18424797 PMCid: PMC2447785, https://doi.org/10.1093/nar/ gkn180

17. Prasad B, Suresh S. Biodegradation of Phthalate esters by Variovorax sp. Sciverse Science Direct. APCBEE Procedia. 2012; 1:16-21. https://doi.org/10.1016/j.apcbee.2012.03.004

18. Jin D, Kong X, Cui B, Bai Z, Zhang H. Biodegradation of Di-nbuty Phthalate by bacterial Consortium LV-1 enriched from river sludge. 2017. 